\title{
The development of the model for
} recognition of prior learning for nurses in South Africa

\author{
Development of RPL guidelines by the policy makers and stakeholders of nursing
}

\author{
T Khanyile, PhD \\ University of the Western Cape
}

\section{Keywords:}

Experience, prior learning, standards, recognition of prior learning

\section{Correspondence address:}

Professor Khanyile

School of Nursing

University of the Western Cape

P/B X 17

Bellville

7535

Tel: (021) 959-3003

Fax: (021) 959-1452

E-mail: tkhanyile@uwc.ac.za

\section{Abstract: Curationis 28(4): 50-56}

The National Qualifications Framework (NQF) was established to address the compartmentalization of education and training, the absence of norms and standards and the need for international recognition. According to the South African Qualifications Authority (1996),this framework was aimed at developing a comprehensive qualifications structure and an integrated approach to education and training in the country (NCHE, 1996:46). Educational institutions, including those for nursing, were challenged with a view to rethink the whole culture of teaching and learning and was counted as knowledge. The major principle of the NQF was the Recognition of Prior Learning (RPL), which had to be persued across all sectors (Musker, 1998: 8). RPL was seen as a means to widen access into learning programs for those who had been historically denied this. The challenge for educational institutions was how to ensure that RPL systems once implemented did not compromise academic standards. Research into methodologies to implement the NF in the absence of mechanisms was then essential. The purpose of the study was to develop and test a RPL model for nurses in South Africa. The study adopted a multi phase decisionsoriented evaluation research design. Stuffelbeam's educational evaluation model was used to guide data collection and analysis. The research questions were incorporated under the different phases of evaluation. The model was development at six levels: level one was at the policy makers level; level two was at the stakeholders; levels three to six were at institutional level where three institutions participated at pilot site for the RPL model development. These levels are presented as tiers in the figure 1 . This article present the results of the model development at the first two levels, which according to Stuffelbeam 's model is the context evaluation for boundary setting. Part two will present the model development at institutional level, involving the input and process evaluation and depicted as tiers three, and four.

\section{Introduction}

The National Qualifications Framework (NQF) was established to address the compartmentalization of education and training, the absence of norms and standards and the need for international recognition,. According to the South African Qualifications Authority (1996),this framework was aimed at developing a comprehensive qualifications structure and an integrated approach to education and training in the country (NCHE, 1996:46). Educational institutions, including those for nursing, were challenged with a view to rethink the whole culture of teaching and learning and what counted as knowledge. The major principle of the NQF was the Recognition of Prior Learning (RPL), which had to be persued across all sectors (Musker, 1998: 8). RPL was seen as a means to widen access into learning programs for those who had been historically denied this. The challenge 
for educational institutions was how to ensure that RPL systems once implemented did not compromise academic standards. Research into methodologies to implement the $\mathrm{QF}$ in the absence of mechanisms was then essential. The purpose of the study was to develop and test a RPL model for nurses in South Africa. The study adopted a multi phase decisionsoriented evaluation research design. Stuffelbeam's educational evaluation model was used to guide data collection and analysis. The research questions were incorporated under the different phases of evaluation. The model was development at six levels: level one was at the policy makers level; level two was at the stakeholders' level; levels three to six were at institutional level where three institutions participated at pilot site for the RPL model development. These levels are presented as tiers in the figure 1. This article presents the results of the model development at the first two levels, which according to Stuffelbeam 's model is the context evaluation for boundary setting. Part two will present the model development at institutional level, involving the input and process evaluation and depicted as tiers three, and four. Part three will present the result of how the model was tested at institutional level, using Stuffelbeams' product evaluation and depicted as tiers five and six (see figure 1). The first two research question formed the basis for this phase.

\section{Research questions}

1. What were the SANC's values and goals with regard to RPL for nurses?

2. How acceptable were these to the nursing stakeholders?

\section{Research design}

Decision-oriented studies emphasize that the evaluation should be used proactively to help improve a program as well as retrospectively to judge its worth. The main questions addressed are: how should a given enterprise be planned (planning decisions), and how should a given plan be carried out (implementation decisions), how should the program be revised (recycling decisions). Numerous methods are used namely, surveys, case studies, needs assessment, advocate teams, observations and quasiexperimental methods (Stuffelbeam, 1987:104). The main advantage of decision-oriented studies is that they encourage educators to use evaluation continuously and systematically in their effort to plan and implement programs that meet educational needs. They also provide a rationale for helping educators to be accountable for to the decisions they have made in the course of implementing the program. In this study the stakeholders were at different levels (policy makers, program managers, program implementers, beneficiaries and consumers) so an appropriate design would be one that catered for different types of decisions at different levels in a systematic and coherent way. Stuffelbeam's Context, Input, Process and Product (CIPP) was used to guide data collection and analysis (Stuffelbeam, 1987:68).

\section{Stuffelbeam's Context, Input, Process and Product (CIPP) model}

The Context Input Process Product (CIPP) model of evaluation was originally developed to provide timely information in a systematic way for decision making as a proactive application of evaluation. It contains three basic steps: first delineation of questions to be answered; second providing information to decision makers for their use and thereby improving ongoing programs; and third, making the decisions about the worth of such programs. As mentioned earlier, this article is based on the context evaluation phase.

\section{Context evaluation for boundary setting}

Determination of context was important in setting the boundaries for the RPL system by establishing the policy makers' frame of reference with regard to RPL for the nursing education system, in order to ensure quality control of such a system (Stuffelbeam, 1992:36).

For the purpose of this phase, three steps were used. The first step involved the researcher reviewing relevant literature, the second step involved the SANC EDCO determining RPL standards and the third step involved the various stakeholders of the profession reviewing the standard. In this manner, the model was developed, and refined before being implemented.

\section{Step one: Literature review}

The purpose of the study was used as a basis for selecting and organizing information to be included in the discussion document. Literature surveyed revealed problems related to innovation. These ranged from differing perceptions between the policy makers who plan the innovation and those of the implementers of the innovation (Wolf, 1996:14). In countries like UK, USA and Canada, RPL practices were occurring at a relatively slow pace due to lack of assessor training (Thomas 1989 Peruniak, 1993). Other problems identified in literature with regards to RPL practices were funding and lack of capacity (Thomas 1998; Butterwoths and Edwards 1993; Clark, Irvanistkaya and Goodwin 2000). Literature on the South African context of RPL revelaed that in South Africa, RPL was inextricably bound into prevailing social relations of power and knowledge. Different sectors (labor, business and education) held differing views and approaches to RPL practices (McMillan, 1997; Harris, 1999). Different RPL models were identified in literature. The first was the process based model by Willngham and Geisinger (1984). This model focus on the steps involved in RPL

The second was the developmental model which was based on Kolb's (1984) notion of experiential learning with a focus on reflection that leads to development (Butterworths 1992:311). The third model identified was the competence based model which used the National Council Vocational Qualifications (NCVQ 1989). The main focus of this model was on assessment of competence ( Usher 1996:36). The result of this first step was a discussion document which was used for the consultative workshop with the SANC Education Committee members.

\section{Step two: Policy makers}

The Education Committee members (EDCO) of the South African Nursing Council formed part of the policy makers' sample during the context evaluation. There were eight members of the EDCO and three Council officers $(N=11)$. See table 1 .

\section{Data collection}

One day consultative workshop was conducted by the researcher, with the SANC EDCO as participants. The EDCO's role was to set the boundaries for the RPL implementation, by identifying their goals, and values with regard to RPL. According to Feustein (1986), a workshop is a small or large group of people who meet to discuss, plan and or produce specific outputs, which may be 
Table1: The Education Committee's sample

\begin{tabular}{|l|l|l|}
\hline Sample characteristics & Present & Absent \\
\hline Nurse educators & 5 & 0 \\
\hline Nurse Representatives & 2 & 0 \\
\hline Department of Health & 1 & 0 \\
\hline Department of Education & 1 & 1 \\
\hline Community representative & 2 & 0 \\
\hline TOTAL & 11 & 1 \\
\hline
\end{tabular}

written, recorded or illustrated (Feustein, 1986:34). According to Ingham and Gilbert (1992), the workshop method minimizes the time required for one to one interviews and also allows for explanations and explorations of difficult concepts. Unlike focus groups, which focus on probing retrospective information, workshops are particularly suited for probing prospective information that may result in learning and development (Ingham and Gilbert.1992:41). A tape recorder was used during the consultative workshops. In preparation for the workshops, participants were given a discussion document that was prepared by the researcher. The researcher provided additional information to ensure clarity about the document. The workshops was highly structured and focused. The first two research question was used as the workshop objectives.

\section{Data analysis}

Data analysis was done deductively by transcribing raw data from the taperecorder and organized sequentially according to the workshop objectives. Data from the flip charts was also incorporated into the transcribed data. Tesch's method of content analysis was used to organize data (Cresswell, 1994:155).The first step involved the researcher reading and re-reading the transcribed data to get the sense of the whole workshop proceedings. The researcher went through the responses to each objective to think about the underlying meanings and these were jotted down. The study of the material culminated in a list of broad topics. Topics with similar meaning were clustered together and arranged as major topics to reduce the length of the topic list. What emerged was a workshop report document which was sent back to the Education Committee members for verification before it was sent to the stakeholders for further refinement. The report contained the EDCO's views on the following: the definition of RPL and RPL process; the assumptions about RPL and the standards there were to be used when implementing RPL practices.

\section{Theoretical concepts}

The key concepts extracted from literature were explored with reference to their meanings, in the context of the South African Education and Training system, and in terms of their relevance to social transformation.

\section{Recognition of Prior learning}

It was agreed that, RPL is based on the notion that how people learn and have learned should be recognized and used to help them progress as learners. However, for maintenance of academic standards, assessment of that learning is important before it can be recognized through credits.

\section{Recognition of Prior Learning process}

The process of recognition of prior learning involved the identification, documentation, assessment and recognition through awards or credits of that learning that was submitted and found to be relevant and current. The currency of experientially acquired learning would be determined by its relevance to the specific program for which recognition was sought. RPL was understood as a means towards an end which might be access into advanced nursing programs or gaining of an academic qualification in nursing for the individual and societal growth and development for the country.

\section{Standards development}

The participants brainstormed various issues concerning the RPL process. They looked at how the proposed system would address issues like the approval of RPL providers, how fees would be determined, how RPL would be marketed to nurses and issues pertaining to administration. The aim of this discussion was an attempt to avoid exploitation of prospective candidates. The participants resolved that the EDCO had a mandate to develop certain standards, based on their values and goals with regard to RPL implementation. The following standards were developed:

Process standards, which included standards for approval, marketing, application, fees determination, those for advising the RPL candidate, notification of results and those for the appeal procedure in case of failure or unfair treatment during assessment.

(b) Academic standards which included standards for assessment and credit granting, (c) Administrative standards.

(d) Access standards

\section{Access for candidates without Standard 10 (at the beginning of the course)}

The EDCO members resolved that for nursing, equivalence to matriculation would include competence in the four basic components namely: numeracy; literacy; social/ contextual knowledge and ethics as set out in the South African Qualifications Authority document (SAQA, 1995). For those candidates with prior nursing knowledge, for example nurse assistants, ambulance training, first aid or any health related experience would have to be assessed and recognised as an equivalent to matriculation or standard 10.

\section{Access at an advanced level}

The EDCO agreed that it would be possible for enrolled nurses to access diploma or degree programs at an advanced level. They felt though that the appropriateness of the level would have to be decided by institutions.

The committee resolved that to maintain its role of quality assurance in the education and training of nurses, it was important to translate the standards into guidelines for the implementation of RPL.. The members placed value on the standards and they saw the EDCO as 
responsible in ensuring that standards were maintained.

\section{Basic assumptions of the RPL model}

The Education Committee members held the following values with regard to what the purpose and process of RPL should be:

(a) Learning takes place anywhere and everywhere, and therefore relevant learning should be recognized, regardless of its site.

(b) RPL is based on the notion that how people learn and have learnt should be recognized and used to help them progress as learners, therefore RPL should lead to both personal and professional development of the individual

(c) Since prior learning cannot be recognized before it is assessed and because not all prior experience leads to learning, it is important to design mechanisms to carefully identify, verify and assess prior learning before crediting it.

(d) Prior learning encompass experiential, non formal, formal certificated and non certificated learning.

(e) RPL practices should reflect transformation, therefore all RPL practices should ensure that access, progression and portability of credits are afforded.

(f) RPL practices should form part of the mainstream of all educational programs and should not be viewed as separate activity.

\section{The purpose/s of RPL}

The EDCO members felt strongly that any RPL practice should provide a practical and pragmatic way for users. Therefore the model developed should:

(a) Identify the standards that will be used as the basis for implementation of the RPL process

(b) Identify the different components of the guidelines namely administrative; process; assessment and quality assurance standards.

(c) Flexible enough to allow for evaluation of each step before commencing the next step. In this way it will allow for built in quality assurance.

\section{Level two :Stakeholders reviewed the RPL standards}

The providers of Nursing Education and Training, the consumers of the profession, namely the Department of Health, the Nursing Service Managers from the different health institutions, the representatives of the nurses, the National Education Health and Allied Workers Union (NEHAWU), Democratic Nurses Organization of South Africa (DENOSA), Hospital Personnel Trade Union of South Africa (HOSPERSA) and South African Democratic Nurses Union (SADNU), were all included as stakeholders. According to the Hospital and Nursing Year book (1999), forty four (44) nursing education institutions in South Africa were registered with the South African Nursing Council. Of these, thirty (30) were Colleges of nursing and fourteen(14) universities. All of these were offering the 4 year Diploma course according to the South African Nursing Council regulation R425 of 1985 as amended (South African Nursing Council Guide 1992:4). According to the Hospital and Nursing Yearbook (1999), there were four hundred and eighty six (486) institutions in the country, both government and private that used the services of trained nurses. There were nine Departments of Health from one in each of the nine provinces, each with a Human Resource Department.

\section{Sampling Criteria}

The following groups were used

a) Nurse educators as providers

b) The Department of Health (Human Resource Division) and Nurse Service Managers as consumers

c) Organizations like Democratic Nurses of South Africa, the Hospital Personnel Trade Union of South Africa and the National Education Health and the Allied Workers Union were also included because they are concerned with the welfare of South African Nurses

\section{Sampling techniques Quota sample}

Three provinces were selected based on their accessibility to the evaluative researcher. Quota sampling was done for each stakeholder category. The provinces selected were Gauteng, Kwa Zulu Natal and Free State. Another reason for the exclusion of the other provinces, besides their inaccessibility, was the existence of related RPL projects in those provinces. During the time of data collection, in Kwa Zulu Natal, there were three colleges, two universities and a Department of Health. In Gauteng, there were ten colleges, three universities offering the Comprehensive Basic Nursing Program, and a Department of Health. In the Free State, there were four colleges, one university and a Department of Health. Therefore, there were twenty-one institutions (21) involved in the study. (See table 2).

Sample size: $\mathrm{N}=185$ participant

\section{Data collection}

The aim of the workshop was to refine the RPL guidelines proposed by the Education Committee. The objectives were

(a) to analyze the proposed guidelines

(b) to add or subtract to the standards as set out in the guidelines, and to comment on the EDCO's proposal with regards to access through RPL

\section{Data analysis}

Proceedings were carefully analysed and the following categories emerged:

a) RPL principles of institutional autonomy versus the rights of candidates:

All stakeholder groups( KZN; FS; Gauteng) felt that the guidelines gave too much autonomy to the provider with little or no attention to the rights of the candidate. Hence the stakeholders strongly recommended that the rights of the candidates be included in the guidelines.

(b) Rights of the RPL candidate:

\section{Information:}

The candidate has a right to adequate information about the fees payable; the duration; form of assessments available and other relevant information.

Assessment and results thereof:

The candidate has the right to faimess during the assessment. $\mathrm{He} / \mathrm{she}$ also has a right to be notified about the results early (within 30 days) after assessment. Post failure counseling

The candidate has a right to post failure counseling where he/she will be given adequate information with regard to the specific areas of weakness in his/her 
Table 2: Stakeholders sample

\begin{tabular}{|l|l|l|l|}
\hline Sample characteristic & Kwa Zulu Natal & Gauteng & Free State \\
\hline D.O.H(Health) & 2 & 0 & 1 \\
\hline Service Manager & 31 & 18 & 15 \\
\hline Nurse educators & 35 & 21 & 25 \\
\hline University & 3 & 3 & 1 \\
\hline DENOSA & 2 & 2 & 3 \\
\hline NEHAWU & 0 & 2 & 2 \\
\hline HOSPERSA & 2 & 4 & 2 \\
\hline SADNU & 1 & 2 & 2 \\
\hline TOTAL & 76 & 58 & 51 \\
\hline
\end{tabular}

performance during the assessment.

\section{Reassessment}

The format that this will take will depend on the policy of the provider institution, but the candidate has a right to this information.

\section{Appeal procedure}

The procedure is to be decided by the provider institution, but the candidate has a right to know what procedure is to be followed.

\section{Support}

The candidate has a right to adequate support during preparation for assessment. This support includes assistance during the preparation of evidence to make a claim as well as support during identification of deficits in knowledge and planning to close them. c) Breakdown of the fee structure

The stakeholders realised the problems involved if fees were standardized, therefore they recommended that the amount charged for RPL should not exceed the amount charged for the programme that the RPL candidate was challenging. It was agreed that in this way, exploitation of candidates by RPL providers would be eliminated (especially in private institutions). One group recommended that the fee structure be broken down in such a way that the candidate would only pay for the services rendered and not the amount of credits. In other words, if the candidate had sufficient evidence and was well versed in the profession for example by portfolio development, he/she should be only charged for registration and assessment.

\section{d) Qualifications of advisors}

After extensive discussion on this issue, stakeholders agreed that advisors should at least be qualified nurse educators although working in the clinical settings.
This recommendation was well received since it would mean a closer working relationship between the service and the colleges/ universities.

\section{e) RPL assessors}

There was a general consensus that assessors should be qualified nurse educators with adequate skills in assessment and currently involved with teaching nursing.

\section{f) Human resource development}

The stakeholders supported the Education Committee's recommendation that people involved with RPL should receive adequate training.

\section{Results of the context evaluation}

These recommendations were incorporated into the proposed guidelines document in boxes under each section and this document was presented to the Education Committee of the South African Nursing Council for further comments and refinement. Responses from the Education Committee were incorporated and a final guidelines document was presented to the full Council and endorsed by the SANC. The proposed guidelines were divided into: RPL process; assessment guidelines and guidelines for granting credits. The policy makers had set the boundaries for RPL for South African nurses, based on what they viewed would be best practice. The stakeholders of the nursing profession had their input into refining the RPL guidelines.

\section{RPL implementation guidelines: Marketing:}

- RPL should be marketed so that the community knows that it is available and that students can proceed quickly through a degree or a diploma.

RPL should be available to all individuals practicing or not currently practicing as nurses, registered or not currently registered with the South African Nursing Council (the latter with an aim of

\section{Application:} registration).

- All applicants should receive adequate information as well as orientation with regard to fees, duration, evaluation methods and exit level outcomes for the particular programme they wish to gain credit for.

All applicants should receive an application form for registration into the program. Registration forms should be user friendly.

Registration forms should act as a contract between the RPL provider institution and the prospective RPL candidate.

Fees:

- RPL candidates should pay the following fees: registration; advising; assessment fees. Fees payable should be determined by the service provided and not by the number of credits.

- Fees charged should not exceed the fees payable for the particular programme for which RPL is sought.

- $\quad$ Fees should be predetermined and valid for at least one academic year.

- Registration fees should be partially or wholly refundable.

\section{Advising/Advisor role:}

- Gives basic career guidance on pathways open to the candidate.

- Is responsible for operational side of the RPL process.

- Assists candidates with the development of the educational plans.

- $\quad$ Should have knowledge of basic career guidance.

- Works in close liaison with the personnel of respective programs ( subject specialists).

- $\quad$ Advises and supports candidates with portfolio development.

- $\quad$ Refers candidates to subject specialists.

- Verifies authenticity of evidence 
submitted.

\section{Assessment:}

- $\quad$ Provider should have the following available for the candidates: examples of portfolios. evaluation methods to be used and the stipulated assessment fee amount to be paid by the candidate .

- Assessment methods chosen should depend on the learning outcomes to be assessed.

- The assessor will decide on the appropriate level of structure of the chosen assessment method. For example, high structure will entail an oral examination and a low structure will entail a loosely structured interview.

- $\quad$ There should be clear identification of evidence required.

- $\quad$ Assessment is to be done by experts in the particular field of study.

Notification of results:

- Candidates have to be informed about the results within a month of final assessment.

- $\quad$ Candidates must to be given particulars about failure.

- Opportunities for post failure Quality assurance:

counseling should be available.

- $\quad$ Reliability should be ensured by using a variety of assessment methods. Multiple assessors should be used until experience indicates that learning can be judged with acceptable consistency.

- $\quad$ Validity will be ensured by using clearly defined learning outcomes identifying performance criteria including any critical factors and standards necessary to meet the learning outcomes.

- Competent assessment will be ensured by providing training for the assessors; use team approach to assessment; emphasize quality and not quantity.

- $\quad$ Credit awards and their transcript entries will be monitored to avoid giving credit twice for the same performance.

- $\quad$ Policies and procedures applied to assessment, including provision for appeal will be fully disclosed and prominently available.

- Assessment programs will be regularly monitored, reviewed, evaluated and revised as needed to reflect changes in the needs being served by assessment.

Academic standards for assessing learning for a credit granting:

- $\quad$ Learning to be credited must fall within the kind of creditable work congruent with the mission and goals of the institution.

- $\quad$ Learning should be applicable outside the specific context in which it was acquired and must serve as a basis for further learning. The person must be able to apply the knowledge and skills in more than one setting.

- Institutional credibility must be maintained throughout the RPL process.

- $\quad$ Learning must be relatively current.

- Learning must shows some relationship to the goal of the degree or diploma program.

- $\quad$ Awards will result from technically sound assessment, taking into consideration of validity and reliability.

Standards for credit granting:

- Credit will be awarded for learning and not experience.

- $\quad$ Credit will be awarded only for learning that has a balance, appropriate to subject, between theory and practice.

- $\quad$ Credit will be given for learning that is appropriate to the academic context in which it is accepted.

\section{Academic rigour}

\section{Threats to validity.}

The major threat to validity, especially in evaluation studies, is error, which can originate from the researcher, the participants, the instrument or the context. The researcher may be biased, or lack experience in conducting research. For this study, the fact that the researcher maintained different roles depending on the different phases, for example, that of a technical consultant during the development phase and as observer during the implementation and testing phases, ensured that bias was limited. Collaboration of the researcher with the stakeholders may also pose a risk to validity. This error is also possible in evaluation studies where the decision makers are people at the macro level of policy making. The other stakeholders may view the role of the evaluator negatively. The evaluator can build in safeguards against this bias by adapting his/her role accordingly. For this particular study the different roles assumed by the evaluative researcher were attempts to eliminate this error. The use of different stakeholder groups for different phases also limited bias. The social context may also be a risk to the validity of the study (Denzin, 1978:102)..

\section{Ethical considerations}

Permission to conduct the study was sought from the following: Directors General of the Departments of Health from the three regions, namely the Free State, KwaZulu Natal and Gauteng. Permission was also sought from the then Acting Registrar of the South African Nursing Council. The Executive Directors of the four identified organisations namely HOSPERSA; DENOSA; SADNU and NEHAWU were invited to send representatives to participate in the workshops. The Principals of the twentytwo institutions were also invited to send personnel to the workshop. Since workshop attendance was voluntary, there was no need for participants to sign consent forms.

\section{Conclusion}

In conclusion, this phase of the model development culminated in the refinement of the RPL guidelines. Comments and contributions from the stakeholders were incorporated into the guidelines and sent back to the Education Committee for their comments and approval. The result of this evaluation was a document containing the refined guidelines collaboratively developed by the policy makers and the representatives of the stakeholders. These guidelines were to form the basis for decisionmaking in the successive phases. The key elements that emerged during this phase were that the: the purpose of RPL (personal and societal growth and development) was accepted, the right of RPL candidates were addressed by the RPL guidelines, decisions were made collaboratively including all relevant stakeholders, assessment standards were accomplished. 


\section{References}

BUTTERWORTHS, C 1992: More than a bite at the APEL. Contrasting models of accrediting prior learning. Journal of Further and Higher Education. 16(3)p3951.

BUTTERWORTHS, C \& EDWARDS, R. 1993: Assessment of prior learning. Open Learning. Vol.3 (1) p234-241.

CLARK, D. IRVANISTKAYA L \& GOODWIN M. 2000: Vehicle design program survey report: Interviews with recent graduates. Technical Report 2000. Central Michigan University College of extended learning.

DENZIN, KK 1978: The research act $2^{\text {m }}$ edition. New York: McGraw- Hill

DENZIN, KK \& LINCOLN 1998: Collecting and interpreting qualitative materials. London:Sage

DAY, $M$ 2000: Report on the development of benchmarks for prior learning assessment and recognition. Practitioners perspective. Canadian Association for Prior Learning Assessment. Ontario.

EVANS, N 1996: Experiential Learning around the world. Employability and the Global Economy. Toronto: Irwin.

EVANS, N 1999: Experiential learning: find it, assess it. What's the problem? Paper presented at the South African Academic Research and Development in Higher Education. June 1999. Learning from Experience Trust.

HARRIS, J 1999: Recognition of Prior Learning: introducing a conceptual framework. South African Journal of Higher Education. 13 (2):47-52.

HILL, D 1997: Aboriginal Access to post secondary education. Prior Learning Assessment and its use within the Aboriginal Programs of Learning. First Nations Institute and loyalist College. Ontario

\section{HOSPITAL AND NURSING} YEARBOOK OF SOUTH AFRICA. 1999: A comprehensive Health Service Information for Southern Africa. Pretoria: Alex Holdings Pharmaceutical Printers and Publishers.

INGHAM, AM \& GILBERT, JK 1992:
The workshop interview technique in higher education. Assessment and evaluation in higher education. 17(1):2944.

KEETON, M 1985: Defining and assuring quality in experiential leaming. New directions for experiential learning. Series No.9. San Francisco: Jossey- Bass Inc.,

McMILLAN, J 1887: Access, learning and contexts: Issues and implications (for RPL).Paper commissioned for HSRC/ UCT/Peninsula Technikon Research and Development in RPL

MICHELSON, E 1996: Beyond Galileo's telescope: Situated knowledge and assessment of experiential learning. Adult Education Quartely. 46 (4): 185-196.

MUSKER, $P$ 1998: Who's afraid of RPL? Joint Education Trust Bulletin. 8 (2):8-10.

NATIONAL COMMISSION ON HIGHER EDUCATION 1996: A framework for transformation. Report 124 of 1996. Pretoria: Department of Education

PEARSON, W 2000: Enhancing adult student persistence. The relationship between prior learning assessment and persistence towards the baccalaureate degree. Experiential Learning.

PERUNIAK, GS 1993: The promise of experiential learning and challenges to its integrity by prior learning assessment. Canadian Journal of University Continuing Education. 19 (\&):13-21.

\section{SOUTH AFRICAN NURSING} COUNCIL 1999: Transformation of Nursing Education and Training in South Africa. Document 15/99. Pretoria: SANC.

SOUTH AFRICAN NURSING COUNCIL 2000: Recognition of prior learning. Document S 1265. Pretoria: SANC

\section{SOUTH AFRICANQUALIFICATIONS} AUTHORITY (SAQA) 1996: The National Qualifications Framework 124/ 1996: A total quality system for education and training in South Africa. Pretoria: SAQA.

STUFFELBEAM, DL 1987: Educational Evaluation and decision making. Illinois: F.E Peacock Publishers.
STUFFELBEAM, DL 1992: The relevance of the CIPP evaluation model for educational accountability. Journal of research and development in education. 5:9-25

THOMAS, A 1998: Prior learning in universities in Ontario. An AideMemoire. Toronto: Council of Toronto Universities.

USHER, R 1996: International case study on recognition of prior learning, contributions to the counseling of adult learners. Studies in Higher Education of Adults.

WOLF, GK 1996: Prior learning assessment: A case study of acceptance of innovation and change. Sydney 